Article

\title{
New Copolymers of Vinylphosphonic Acid with Hydrophilic Monomers and Their Eu ${ }^{3+}$ Complexes
}

\author{
Olga Nazarova *(iD, Elena Chesnokova, Tatyana Nekrasova, Yulia Zolotova (D), Anatoliy Dobrodumov (D), \\ Elena Vlasova, Andrei Fischer (D), Marina Bezrukova and Eugeniy Panarin
}

Citation: Nazarova, O.; Chesnokova,

E.; Nekrasova, T.; Zolotova, Y.;

Dobrodumov, A.; Vlasova, E.; Fischer,

A.; Bezrukova, M.; Panarin, E. New

Copolymers of Vinylphosphonic

Acid with Hydrophilic Monomers

and Their $\mathrm{Eu}^{3+}$ Complexes. Polymers

2022, 14, 590. https://doi.org/

$10.3390 /$ polym 14030590

Academic Editors: Asterios

(Stergios) Pispas and

Dimitrios Bikiaris

Received: 6 December 2021

Accepted: 27 January 2022

Published: 31 January 2022

Publisher's Note: MDPI stays neutral with regard to jurisdictional claims in published maps and institutional affiliations.

Copyright: (C) 2022 by the authors. Licensee MDPI, Basel, Switzerland. This article is an open access article distributed under the terms and conditions of the Creative Commons Attribution (CC BY) license (https:// creativecommons.org/licenses/by/ $4.0 /)$.
Federal State Budgetary Institution of Science Institute of Macromolecular Compounds, Russian Academy of Sciences (IMC RAS), V.O. Bolshoy pr. 31, 199004 Saint Petersburg, Russia; lenavitalena@mail.ru (E.C.); polar@macro.ru (T.N.); julia.i.zolotova@gmail.com (Y.Z.); anatoliy.dob@gmail.com (A.D.); spectra@imc.macro.ru (E.V.); andreasfischer@mail.ru (A.F.); bezrukova@imc.macro.ru (M.B.); lab.2@mail.ru (E.P.) * Correspondence: nazaro@hq.macro.ru; Tel.: +7-(812)-328-72-60

\begin{abstract}
Free radical copolymerization is used for the synthesis of novel water-soluble copolymers of vinylphosphonic acid with 2-deoxy-2-methacrylamido-D-glucose or 4-acryloylmorpholine, with varied compositions and molecular masses, as well as for the synthesis of copolymers of vinylphosphonic acid with acrylamide. The obtained copolymers contain 6-97 mol.\% of vinylphosphonic acid units, and their molecular masses vary from $5 \times 10^{3}$ to $310 \times 10^{3}$. The monomer reactivity ratios of vinylphosphonic acid and 2-deoxy-2-methacrylamido-D-glucose in copolymerization are determined for the first time, and their values are 0.04 and 9.02, correspondingly. It is demonstrated that the synthesized copolymers form luminescent mixed-ligand complexes with $\mathrm{Eu}^{3+}$, thenoyltrifluoroacetone, and phenanthroline. The influence of the comonomer's nature on the intensity of the luminescence of complex solutions is revealed.
\end{abstract}

Keywords: water-soluble copolymers of vinylphosphonic acid; 2-deoxy-2-methacrylamido-D-glucose; 4-acryloylmorpholine; complexes of $\mathrm{Eu}^{3+}$

\section{Introduction}

Poly(vinylphosphonic acid) (PVPA) is applied as a component of anticorrosive coatings, polymeric electrolyte membranes, dental cements, and in bone tissue engineering [1-4]. A promising direction for the use of VPA polymers is associated with their antimicrobial and antiviral activities; in particular, they are active against coronavirus infection [5,6].

It is also known that VPA polymers are capable of binding with various metal cations [7] and luminescent metal-polymer complexes, for example, with $\mathrm{Eu}^{3+}$. Based on this, VPA polymers can potentially be used to visualize the interaction of polymers with viral particles and cells.

Currently, various fluorophores are used for such visualization, including fluorescein, dansyl chloride, and rhodamine [8]. The coordination of compounds with $\mathrm{Eu}^{3+}$ has attracted considerable interest because of their fascinating luminescence properties, such as the quasi-monochromaticity of their radiation (the half-width of the luminescence bands is 5-10 nm, while for organic chromophores, it is more than $100 \mathrm{~nm}$ ), the stability of their radiation over time, the independence of the position of the luminescence bands from the nature of the ligand and solvent, a large Stokes shift in complexes, and the high values of excited state lifetimes $(\approx 1000 \mu \mathrm{s})$, meaning that they may be used as luminescent sensors for visualization in medicine and biology [9]. It is known that the use of polymer complexes in biology and medicine makes it possible to prolong their action in comparison with low molecular weight complexes [10]. Due to the high binding constants of VPA with ions of polyvalent ions (lanthanides) [11], the preparation of $\mathrm{Eu}^{3+}$ complexes with such polymers is of considerable interest. However, these complexes do not luminesce. In this 
connection, it is relevant to study the possibility of obtaining luminescent complexes using the "antenna effect" [12], based on the transfer of electronic excitation energy from the triplet level of the ligand to the excited level of the lanthanide, where luminescence occurs. It should be taken into account that the efficiency of energy transfer depends not only on the energy of the triplet level of the ligand, but also on the nature of the substituents in it, their interaction with the environment, and the concentration of the complexing units in the macromolecule [13,14].

One way to vary the properties is to use copolymers. The use of comonomers of different natures makes it possible to change the microenvironment of the chelate group.

The aim of this work was to develop synthetic methods to prepare and study novel original copolymers of VPA with 2-deoxy-2-methacrylamido-D-glucose (MAG) and 4acryloylmorpholine (4-AM), with varied compositions and molecular masses; to prepare VPA copolymers with acrylamide (AA) (Figure 1); and to estimate the ability of the synthesized copolymers to form luminescent complexes with $\mathrm{Eu}^{3+}$ ions, and examine the photophysical properties of such complexes.<smiles>CC(C)(C)CC(C(C)(C)C)P(=O)(O)O</smiles>

I

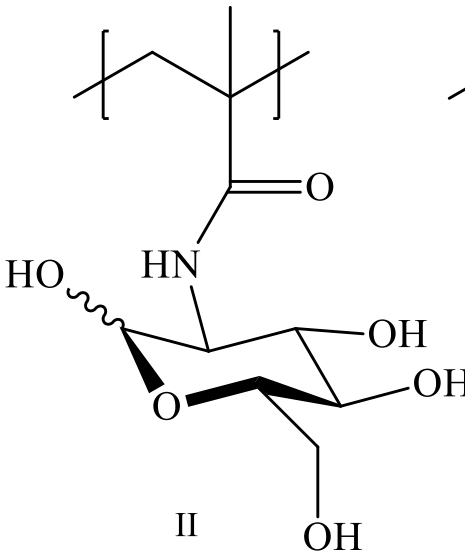

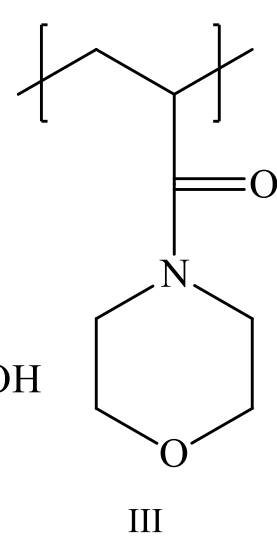<smiles>CC(C)(C)CC(C(N)=O)C(C)(C)C</smiles>

IV

Figure 1. VPA (I), MAG (II), 4-AM (III), AA (IV) units.

The random double and triple copolymers of VPA with methyl acrylate, acrylonitrile [15], acrylic and methacrylic acids [4,16], acrylamide [17], styrene [18], N-vinylpyrrolidone [19], $\mathrm{N}$-vinylimidazole [20], etc., are known. The graft and block copolymers of VPA have been synthesized $[2,3,21]$. However, the VPA copolymers with MAG and 4-AM and their luminescent complexes with $\mathrm{Eu}^{3+}$ are not described in the literature.

\section{Materials and Methods}

\subsection{Materials}

VPA, 4-AM, 2,2-dimethylformamide (DMFA), 2,2'-azobisisobutyronitrile (AIBN), and 2,2'-azobis(2-methylpropionamidine) dihydrochloride (AMP) were purchased from Aldrich (Germany). VPA was washed with diethyl ether to remove the inhibitor and dried under vacuum. Then, 4-AM and DMFA were distilled under vacuum. MAG was synthesized according to the technique described in [22]. The physico-chemical parameters of all substances corresponded to the literature values.

\subsection{Methods}

\subsubsection{Synthesis of (Co)Polymers}

The VPA homopolymer and copolymers were synthesized via free radical copolymerization in an argon atmosphere at $60^{\circ} \mathrm{C}$ for $24 \mathrm{~h}$. When the process was carried out in organic solvents, AIBN was used as an initiator; in aqueous solutions, AMP was employed. In the experiments for the determination of monomer reactivity ratios, the copolymer yields did not exceed $5 \mathrm{wt} . \%$. 
To purify the copolymers from low molecular weight admixtures, they were dialyzed against water. Spectra/Por 7 membranes (Spectrum Laboratories, Inc., Seguin, TX, USA) were used; these membranes allow one to remove substances with molecular masses below 1000. Then, the products were isolated by freeze drying.

\subsubsection{Compositions of Copolymers}

The compositions of the copolymers were determined using $1 \mathrm{H}$ and 31P NMR spectroscopy methods. The NMR spectra of the solutions of samples in $\mathrm{D}_{2} \mathrm{O}$ were registered with the aid of a Bruker Avance 400 spectrometer (Bruker, Karlsruhe, Germany). In addition, 2-Methacryloyloxyethyl phosphorylcholine (MPC) was used as an external standard.

\subsubsection{IR Spectroscopy}

The IR spectra of samples were obtained at room temperature in the $400-4000 \mathrm{~cm}^{-1}$ wavenumber range (resolution: $4 \mathrm{~cm}^{-1}$; number of scans: 30) using a "Vertex 70" FTIR spectrometer (Bruker, Ettlingen, Germany) equipped with a ZnSe attenuated total reflection (ATR) attachment ("Pike Technologies", Madison, WI, USA). During the registration of the ATR spectra, a correction was made that took into account light penetration depth as a function of wavelength.

\subsubsection{Determination of Molecular Masses of Polymers}

Diffusion coefficients $D$ and sedimentation coefficients $s$ were measured using the experimental setups equipped with polarization interferometers described in [23]. The polarization interferometers installed in the ultracentrifuge and the diffusiometer made it possible to carry out measurements at relatively low concentrations of samples (less than $0.15 \times 10^{-2} \mathrm{~g} / \mathrm{cm}^{3}$ ); besides, it was not necessary to study concentration dependences.

The molecular masses (MM) of the samples were calculated from the values of diffusion coefficients $D$ and sedimentation coefficients $s$, measured in $0.1 \mathrm{~N} \mathrm{NaCl}$ solution at $24{ }^{\circ} \mathrm{C}$ according to the Svedberg formula:

$$
M_{s D}=(s / D) \times R T /\left(1-\bar{v} \rho_{0}\right)
$$

where $R$ is the universal gas constant, $T$ is the absolute temperature $(K), \bar{v}$ is the partial specific volume determined by pycnometry, and $\rho_{o}$ is the density of a solvent [23]. The $\bar{v}$ values of the copolymers were calculated additively from the mass densities $\left(\bar{v}^{-1}\right)$ of the copolymer components, taking into account sample compositions. The values measured by pycnometry were equal to $0.529 \mathrm{~cm}^{3} / \mathrm{g}$ for poly(vinylphosphonic acid), $0.667 \mathrm{~cm}^{3} / \mathrm{g}$ for poly-MAG, $0.74 \mathrm{~cm}^{3} / \mathrm{g}$ for poly(4-acryloylmorpholine), and $0.77 \mathrm{~cm}^{3} / \mathrm{g}$ for polyacrylamide. The values of the buoyancy factor $\left(1-v \rho_{0}\right)$ ranged from 0.24 to 0.46 , depending on the copolymer composition.

\subsubsection{Synthesis of Complexes with $\mathrm{Eu}^{3+}$}

Thenoyltrifluoroacetone (TTA) and phenanthroline (PHEN) were used as sensitizers for $\mathrm{Eu}^{3+}$ luminescence. Calculated amounts of solutions of $\mathrm{EuCl}_{3} \cdot 6 \mathrm{H}_{2} \mathrm{O}$, TTA, and PHEN (concentration: $5 \times 10^{-3} \mathrm{~mol} / \mathrm{L}$ ) were consequently added to the aqueous solution of a copolymer (concentration of VPA units: $1 \times 10^{-4} \mathrm{~mol} / \mathrm{L}$ ). The following molar ratios were used: VPA unit/ $\mathrm{Eu}^{3+} / \mathrm{TTA} / \mathrm{PNEN}=3: 1: 2: 1$. The solutions were left to stand for $1 \mathrm{~h}$ at room temperature.

\subsubsection{UV-Vis Spectra}

The electronic absorption spectra of copolymer solutions were obtained with the use of an SF-256 UVI spectrophotometer ("OOO LOMO Photonika", Russia). 


\subsubsection{Excitation and Luminescence Spectra}

The excitation and luminescence spectra of solutions were registered with the use of an LS-100 spectrofluorometer ("PTI", London, ON, Canada). The widths of the entrance and exit slits of the monochromator were equal to $4 \mathrm{~nm}$. The measurements were carried out at $25^{\circ} \mathrm{C}$ in a $1 \mathrm{~cm}$ quartz cuvette.

\section{Results and Discussion}

Table 1 presents the synthesis conditions and characteristics of the prepared MPC copolymers.

Table 1. Synthesis conditions and characteristics of VPA copolymers $\left(\mathrm{M}_{1}\right)$.

\begin{tabular}{|c|c|c|c|c|c|c|c|c|c|}
\hline \multirow[b]{2}{*}{$\mathbf{N}$} & \multicolumn{6}{|c|}{ Conditions of Copolymerization ${ }^{a}$} & \multicolumn{3}{|c|}{$\begin{array}{l}\text { Characteristics of } \\
\text { Copolymers }\end{array}$} \\
\hline & {$\left[\mathbf{M}_{2}\right]$} & $\begin{array}{c}{\left[\mathbf{M}_{1}\right]:\left[\mathbf{M}_{2}\right]} \\
\text { mol. } \%\end{array}$ & $\begin{array}{c}{\left[\mathbf{M}_{1}+\mathbf{M}_{2}\right]} \\
\quad \text { wt. } \%\end{array}$ & Solvent & $\mathbf{I}^{\mathbf{b}}$ & $\begin{array}{c}{[\mathbf{I}],} \\
\mathbf{w t} \% \text { of } \\
{\left[\mathbf{M}_{1}+\mathbf{M}_{2}\right]}\end{array}$ & $\begin{array}{l}\text { Yield, } \\
\%\end{array}$ & $\begin{array}{l}{\left[\mathrm{M}_{1}\right] \text {, }} \\
\text { mol.\% }\end{array}$ & $\underset{10^{-3}}{\mathrm{M}_{\mathrm{SD}} \times}$ \\
\hline $1^{c}$ & - & 100:0 & 80 & $\mathrm{H}_{2} \mathrm{O}$ & AMP & 1 & 54 & 100 & 30 \\
\hline 2 & MAG & $25: 75$ & 10 & $\mathrm{H}_{2} \mathrm{O}$ & AMP & 2 & 86 & 6 & 117 \\
\hline 3 & MAG & $50: 50$ & 10 & DMFA & AIBN & 2 & 71 & 12 & 20 \\
\hline 4 & MAG & $90: 10$ & 10 & $\mathrm{H}_{2} \mathrm{O}$ & AMP & 2 & 29 & 53 & 5 \\
\hline 5 & 4-AM & $25: 75$ & 20 & Methanol & AIBN & 2 & 76 & 13 & 77 \\
\hline 6 & $4-\mathrm{AM}$ & $25: 75$ & 20 & $\mathrm{H}_{2} \mathrm{O}$ & AMP & 2 & 82 & 14 & 310 \\
\hline 7 & 4-AM & $50: 50$ & 20 & $\mathrm{H}_{2} \mathrm{O}$ & AMP & 1 & 38 & 56 & 33 \\
\hline 8 & 4-AM & $90: 10$ & 20 & $\mathrm{H}_{2} \mathrm{O}$ & AMP & 1 & 27 & 97 & 10 \\
\hline 9 & AA & $25: 75$ & 20 & Methanol & AIBN & 2 & 77 & 13 & 40 \\
\hline 10 & AA & $25: 75$ & 20 & DMFA & AIBN & 2 & 93 & 28 & 25 \\
\hline 11 & AA & $25: 75$ & 20 & $\mathrm{H}_{2} \mathrm{O}$ & AMP & 2 & 74 & 14 & 240 \\
\hline 12 & AA & $50: 50$ & 20 & $\mathrm{H}_{2} \mathrm{O}$ & AMP & 1 & 56 & 31 & 70 \\
\hline 13 & AA & $90: 10$ & 20 & $\mathrm{H}_{2} \mathrm{O}$ & AMP & 1 & 11 & 63 & 7 \\
\hline
\end{tabular}

a $24 \mathrm{~h}, 60^{\circ} \mathrm{C},{ }^{\mathrm{b}} \mathrm{I}$-initiator, ${ }^{\mathrm{c}} 80^{\circ} \mathrm{C}$.

Figure 2 demonstrates FTIR spectra of the synthesized PVA-AA copolymer and the corresponding homopolymers. The spectrum of the VPA homopolymer contains the following bands: $1120 \mathrm{~cm}^{-1}$ (hydrogen bonded $\mathrm{P}=\mathrm{O} \mathrm{P}=\mathrm{O}$ participating; $980 \mathrm{~cm}^{-1}$ and $910 \mathrm{~cm}^{-1}$ (P-O vibrations) [24,25]. The spectrum of the AA homopolymer includes the bands near $1650 \mathrm{~cm}^{-1}$ that correspond to the $\mathrm{C}=\mathrm{O}$ vibration of the amide $\mathrm{I}$ band. The spectrum of the AA-VPA copolymer contains all the indicated bands of both comonomer units (Figure 2). 

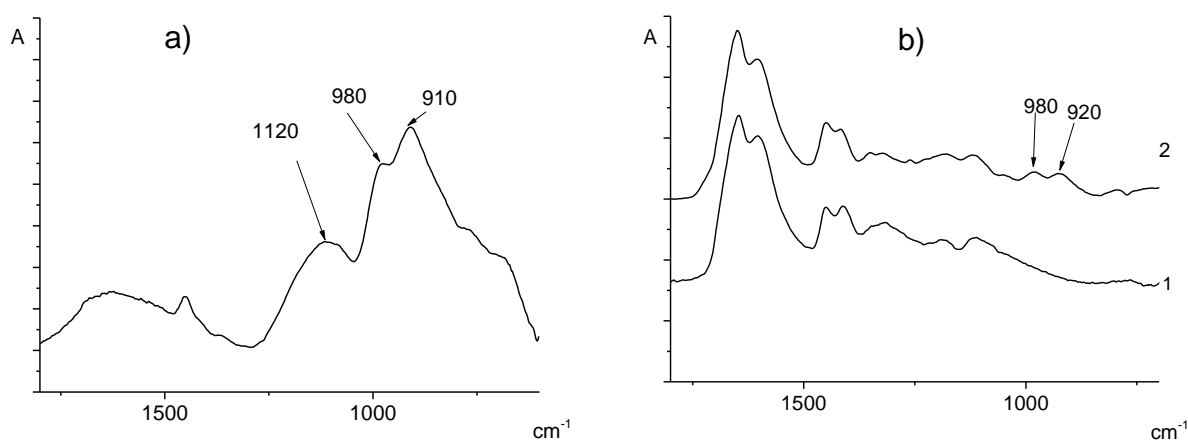

Figure 2. FTIR spectra of VPA homopolymer (a), AA homopolymer (b,1), AA-VPA copolymer (Experiment 11, Table 1) $(\mathbf{b}, 2)$.

The spectrum of poly(4-acryloylmorpholine) contains the characteristic bands at $1620 \mathrm{~cm}^{-1}$ (amide I) and $1113 \mathrm{~cm}^{-1}$ (related to vibrations of the C-O-C fragment of the cyclic ether). Unlike the bands of the 4-AM units, the bands related to the VPA units in the spectrum of the 4-AM-VPA copolymer are poorly resolved; for the purpose of the detailed study of these peaks, the difference spectrum of the 4-AM-VPA copolymer and poly(4-acryloylmorpholine) was obtained. In this spectrum, the peaks at $1155 \mathrm{~cm}^{-1}$, $980 \mathrm{~cm}^{-1}$, and $920 \mathrm{~cm}^{-1}$, typical for the VPA units, were observed (Figure 3).

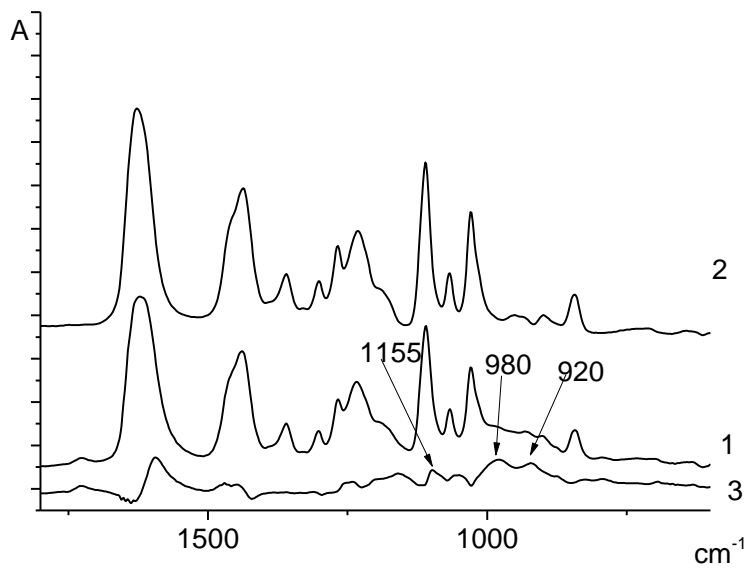

Figure 3. FTIR spectra of poly(4-acryloylmorpholine) (1), 4-AM-VPA copolymer (Experiment 5, Table 1) (2), the difference spectrum (3).

The spectrum of the MAG homopolymer (Figure 4) contains the characteristic amide I $\left(1650 \mathrm{~cm}^{-1}\right)$ and amide II $\left(1550 \mathrm{~cm}^{-1}\right)$ bands, as well as the peak related to the vibrations of the glycoside ring $\left(1000 \mathrm{~cm}^{-1}\right)$. The amide I band of the MAG units in the spectrum of the MAG-VPA copolymer becomes less intense, and it is widened and shifted (from $1650 \mathrm{~cm}^{-1}$ to $1630 \mathrm{~cm}^{-1}$ ); besides, the shape of the band attributed to the glycoside ring near $1000 \mathrm{~cm}^{-1}$ changes. The peaks attributed to the VPA units are poorly resolved. As in the case of the 4-AM-VPA copolymer, the difference spectrum (obtained from MAG-VPA and the MAG homopolymer) contains the bands at $980 \mathrm{~cm}^{-1}$ and $890 \mathrm{~cm}^{-1}$ typical of VPA units. The shift of one band from $910 \mathrm{~cm}^{-1}$ to $890 \mathrm{~cm}^{-1}$, and the changes in the MAG bands, are apparently related to the differences in the microenvironments of these units in the homopolymer or the copolymer. 


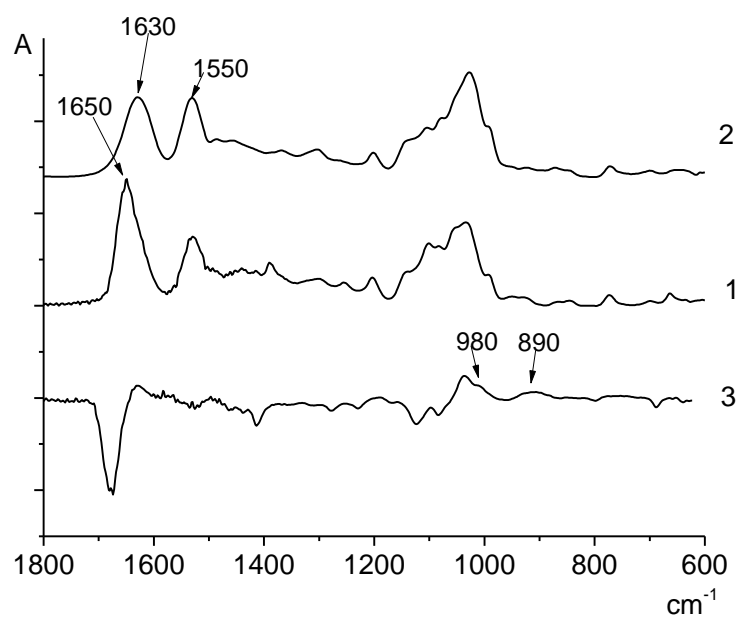

Figure 4. FTIR spectra of MAG homopolymer (1), MAG-VPA copolymer (2) (Experiment 3, Table 1), the difference spectrum (3).

The compositions of the copolymers were determined through NMR spectroscopy [4]. Unfortunately, in all cases in the ${ }^{1} \mathrm{H}$ NMR spectra of all copolymers, the signals from the protons of the VPA backbone at around 1.0-2.5 ppm (Figures 5 and 6) overlap with the proton signals of the comonomers. Therefore, it is impossible to determine explicitly the composition of the copolymers from the ${ }^{1} \mathrm{H}$ NMR spectra only; for this reason, a combination of $1 \mathrm{H}$ and ${ }^{31} \mathrm{P}$ NMR spectroscopy was used. A phosphorus-containing compound (2-methacryloyloxyethyl phosphorylcholine (MPC)) was used as a concentration reference mark, because in all cases, the signals of the two protons from the MPC of the double bond (that are located near 5.5-6.5 ppm, Figure 6) are not overlapped with the signals of the comonomer units.

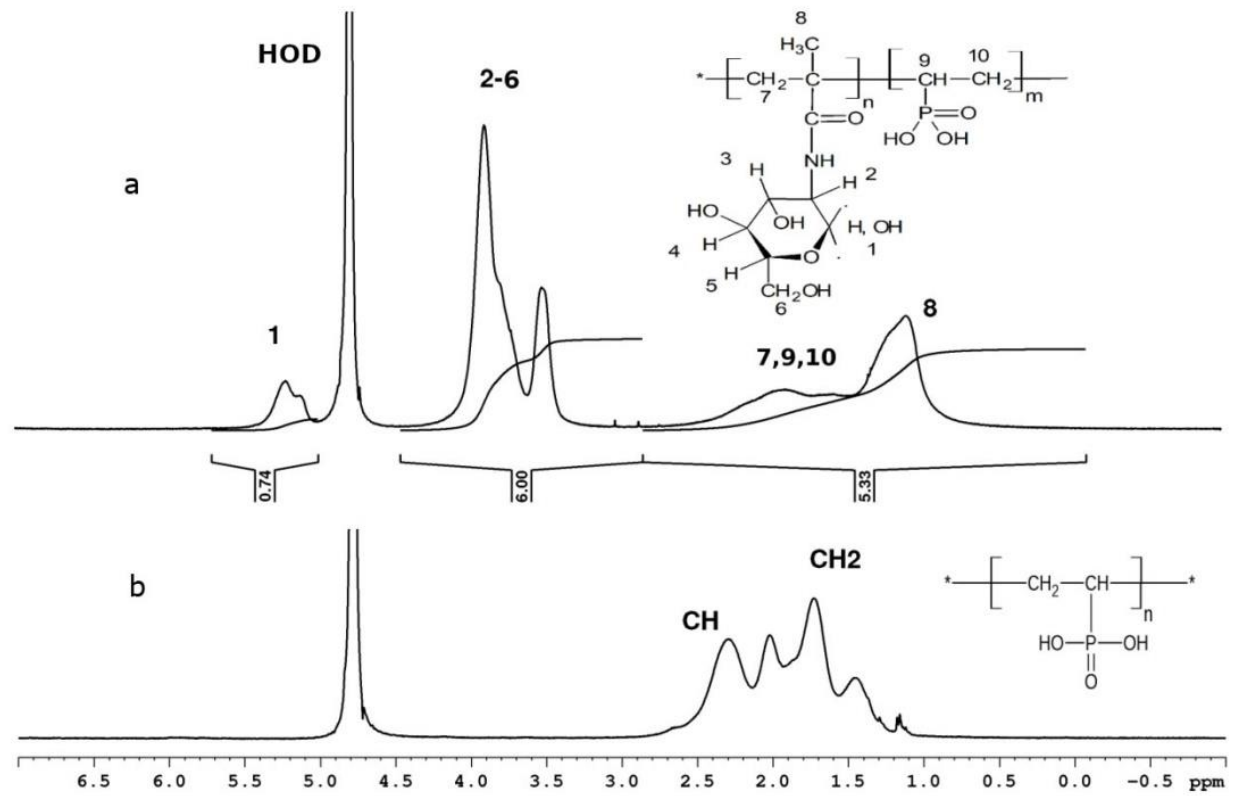

Figure 5. ${ }^{1} \mathrm{H}$ NMR spectra of MAG-VPA copolymer (Experiment 3 , Table 1) (a), PVPA (b) in $\mathrm{D}_{2} \mathrm{O}$. 


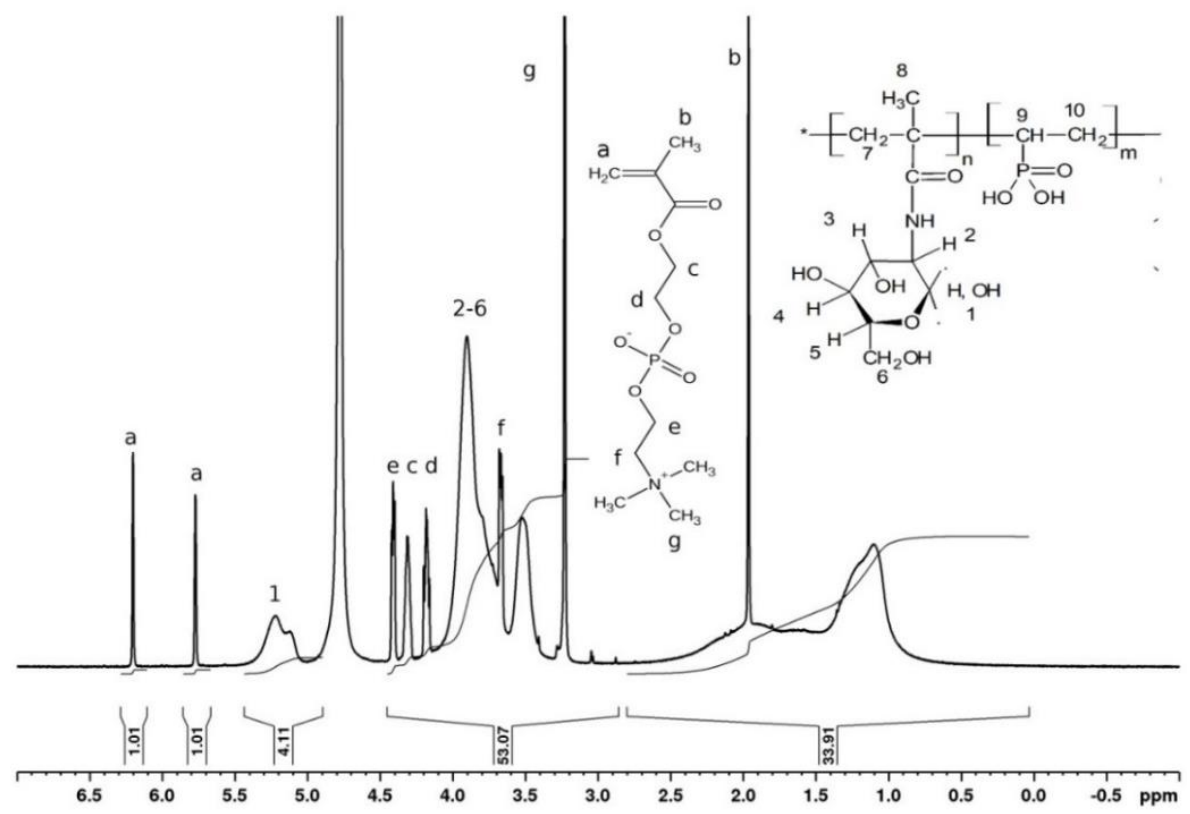

Figure 6. ${ }^{1} \mathrm{H}$ NMR spectrum of the mixture containing MAG-VPA copolymer (Experiment 3, Table 1) and $\mathrm{MPC}$ in $\mathrm{D}_{2} \mathrm{O}$.

For example, in the ${ }^{1} \mathrm{H}$ NMR spectrum of the mixture of copolymer VPA-MAG (Experiment 3, Table 1) and MPC, both signals of protons $2-6$ of the MAG ring (six protons) and the signals of 17 protons $\mathrm{c}, \mathrm{d}, \mathrm{e}, \mathrm{f}$, and $\mathrm{g}$ of MPC are observed in the 3.0-4.5 ppm range (Figure 6). When the intensities of the MPC signals in the 5.5-6.5 ppm range were normalized to unity, the integral intensity of the signals of protons 2-6 of the MAG ring (A) was equal to the integral intensity of all signals in the 3.0-4.5 ppm range (B), minus the intensity of the 17 MPC protons. Correspondingly, the integral intensity per one MAG proton $(C)$ is equal to $C=A / 6=(B-17) / 6$. The molar ratio between MAG and MPC is MAG:MPC = C:1

The ${ }^{31} \mathrm{P}$ NMR spectrum presented in Figure 7 was used to determine the molar ratio $\mathrm{Y}=\mathrm{VPA} / \mathrm{MPC}$. It was calculated as a ratio of the integral intensities of the MPC signal near $-0.7 \mathrm{ppm}(\mathrm{D})$ and the copolymer signals in the 20-35 ppm area (E) (Y = E/D) (see Figure 7). Then, the molar ratio between the copolymer units in a sample can be calculated as $\mathrm{F}=\mathrm{C}: \mathrm{Y}=\mathrm{C}: \mathrm{E} / \mathrm{D}$. For copolymer 3 (Table 1$), \mathrm{F}=(53.07-17) / 6: 1.01=6: 1$. Therefore, the molar composition is the following: $86 \mathrm{~mol} \%$ of MAG and $14 \mathrm{~mol} . \%$ of VPA.

The compositions of all the synthesized copolymers were calculated in a similar way.

In all cases, the copolymers contained less VPA units than the initial reaction mixture (Table 1), which is especially noticeable in the case of the MAG-containing copolymers.

Using water instead of organic solvents (DMFA or methanol), other things being the same, leads to an increase in the molecular masses of the products (Experiments 5, 6, and 9-11 in Table 1). This is due to the extremely low values of the chain transfer constants in water [26,27].

All copolymers were soluble in water.

The described copolymers MAG-VPF and 4-AM-VPA were obtained for the first time; thus, there are no literature data on the reactivities of the used comonomers in the course of copolymerization. It was interesting to estimate their relative activities. The compositions of the MAG-VPA copolymers were determined when the yields did not exceed $5 \mathrm{wt} . \%$. It was found that at all comonomer ratios, the copolymers formed at the early stages of the copolymerization process were heavily depleted with VPA units (in comparison with the initial monomer mixture). 

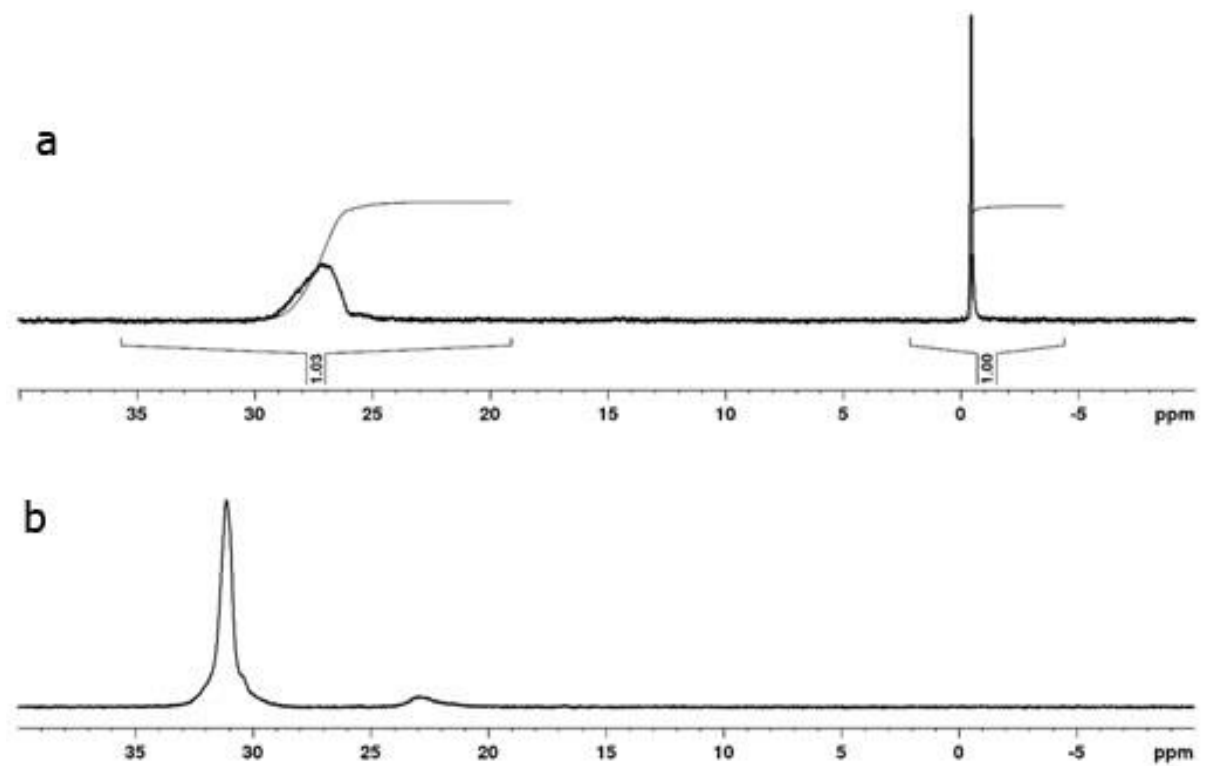

Figure 7. ${ }^{31} \mathrm{P}$ NMR spectra of the mixture of MAG-VPA copolymer with MPC (a) and PVPA (b) in $\mathrm{D}_{2} \mathrm{O}$.

The relative reactivities of the monomers were calculated using the Fineman-Ross, and the Kelen-Tüdös methods [28,29]. The following values were obtained: $\mathrm{r}_{\mathrm{VPA}}=0.04$; $\mathrm{r}_{\mathrm{MAG}}=9.02$. Thus, VPA is a considerably less active comonomer during copolymerization with MAG. The low activity of VPA has been reported earlier in copolymerization with acrylic acid [4] and N-vinylpyrrolidone [19]. According to the suggested mechanism, VPA polymerization proceeds with the formation of VPA anhydride cycles and the formation of various types of radicals. It is assumed that this process leads to a decrease in the relative reactivity of VPA during polymerization [4,30].

In all cases, an increase in the content of this monomer, with low reactivity in the initial comonomer mixture, led to a decrease in copolymer yield and the $\mathrm{M}_{\mathrm{SD}}$ of the product (Table 1). This effect was registered in work [16].

The binding constants of lanthanide ions by phosphonic acid and its derivatives $(\mathrm{Kb})$ are in the range of $10^{5}-10^{6}(17,600-313,000)$ [11]; however, the forming complexes do not exhibit luminesce. This is due to the fact that the luminescence intensity of individual lanthanide ions is due to $\mathrm{f}-\mathrm{f}$ transitions within individual ions, since these transitions are forbidden (the Laporte rule). Therefore, the absorption and, accordingly, the luminescence of lanthanide ions are extremely low. The discovery of the luminescence sensitization of lanthanide ions by an organic ligand, the "antenna effect" [12], allows one to bypass the direct excitation of the lanthanide ion, which is prohibited by the selection rules. The introduction of an organic ligand that effectively absorbs the energy of electron excitation and transfers it from the triplet level to the resonance level of the lanthanide, from which luminescence occurs, is widely used in the formation of the luminescence complexes of lanthanide ions. The position of the triplet level of the ligand in relation to the resonant level of the lanthanide ion [31] is the basic factor for improving the efficiency of sensitization. In phosphonic acid (co)polymers, the lanthanide ion can coordinate two phosphonate groups. However, the $\mathrm{OH}$ groups in phosphonates are unable to saturate the coordination sphere of lanthanide ions. Owing to the high coordination numbers (8-10) of the lanthanide complexes [14], it is possible to introduce a neutral ligand and vary the luminescent properties in a regulable manner. In this work, thenoyltrifluoroacetone (TTA) and phenanthroline (PHEN) molecules were used as luminescence sensitizers for $\mathrm{Eu}^{3+}$ ions (Figure 8). 
<smiles>O=C(CC(=O)C(F)(F)F)c1cccs1</smiles>

TTA<smiles>c1cnc2c(c1)ccc1cccnc12</smiles>

PHEN

Figure 8. TTA and PHEN structures.

Figure 9 presents as an example of a normalized electronic absorption spectra растворов of the following solutions: $\mathrm{Eu}^{3+} / 4-\mathrm{AM}-\mathrm{VPA}$ copolymer (Experiment 5, Table 1) (1), $\mathrm{Eu}^{3+}$ /4-AM-VPA copolymer/TTA (2), Eu ${ }^{3+} / 4-\mathrm{AM}-\mathrm{VPA}$ copolymer/TTA/PHEN (3), TTA (4), and phenanthroline (5). The UV spectra were normalized to the optical density of the TTA solution in the band at $266 \mathrm{~nm}$.

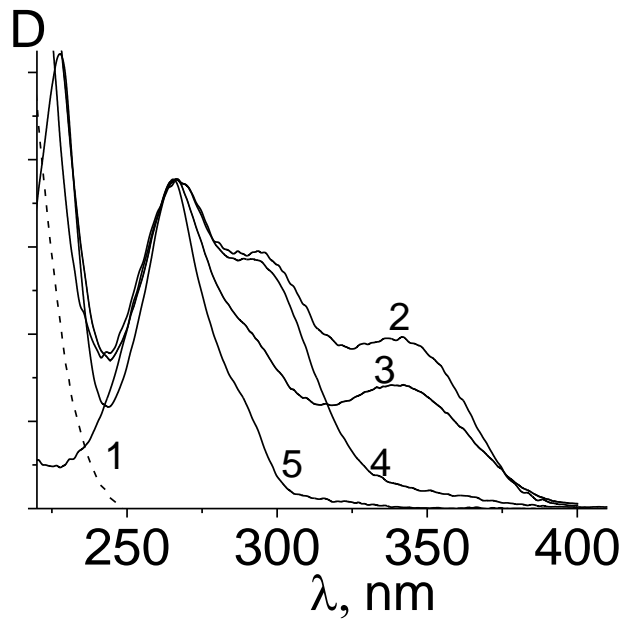

Figure 9. Normalized electronic absorption spectra of aqueous solutions: $\mathrm{Eu}^{3+} / 4-\mathrm{AM}-\mathrm{VPA}$ copoly-

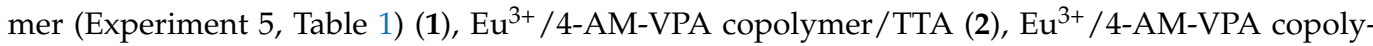
mer/TTA/PHEN (3), TTA (4), and phenanthroline (5).

The UV spectra of the solutions of the VPA-MAG and VPA-AA copolymers have a similar shape.

It is known that TTA forms complexes with multivalent metal ions, including lanthanides (which is indicated by the appearance of a new band in the long-wavelength region of the TTA electronic spectra). Spectra (2) and (3) contain the peak at $\lambda=340 \mathrm{~nm}$ that indicates the formation of the complex with $\mathrm{Eu}^{3+}$.

Figure 10 shows the excitation (1) and photoluminescence (2) spectra of $\mathrm{Eu}^{3+} / \mathrm{TTA}$ (a), solutions of $\mathrm{Eu}^{3+} / 4-\mathrm{AM}-\mathrm{VPA} / \mathrm{TTA}$ (b), solutions of $\mathrm{Eu}^{3+} / 4-\mathrm{AM}-\mathrm{VPA} / \mathrm{PHEN}$ (c), solutions of $\mathrm{Eu}^{3+} / \mathrm{PHEN}(\mathrm{d})$, and solutions of $\mathrm{Eu}^{3+} / 4-\mathrm{AM}-\mathrm{VPA} / \mathrm{TTA} / \mathrm{Phen}(\mathrm{e})$.

It was found that the VPA copolymers with MAG, 4-AM, and AA form luminescent complexes with $\mathrm{Eu}^{3+}$ in the presence of TTA or PHEN. With Eu ${ }^{3+}$ in a solution of a polymer complex, the so-called "polymer effect" is due to the displacement of water molecules from the coordination sphere of a low molecular complex and the substitution of a part of the water molecules by copolymer phosphonate groups. 

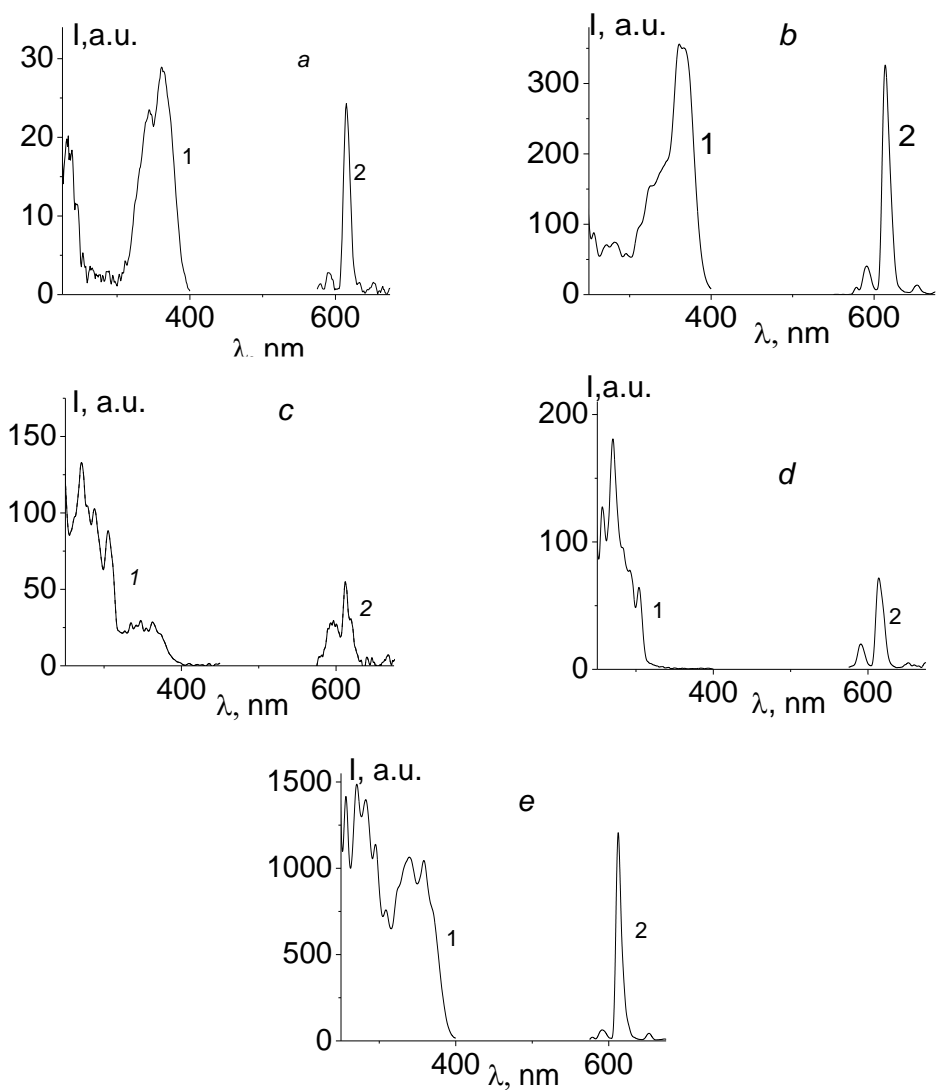

Figure 10. Excitation (1) and photoluminescence (2) spectra of solutions of $\mathrm{Eu}^{3+} / \mathrm{TTA}(\mathbf{a}), \mathrm{Eu}^{3+} / 4-\mathrm{AM}$ -

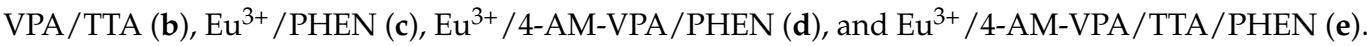

The comparison of the absorption and excitation spectra of the complex Eu ${ }^{3+} / 4-\mathrm{AM}-$ VPA copolymer/TTA (Figure 9, spectrum 2 и Figure 10b, spectrum 1) shows that their shapes differ. Pronounced differences in the shape between the absorption and excitation spectra in the lanthanide complexes indicate the sensitization efficiency, because the ratio between the bands, which originated from the ligand absorption and from the absorption of the lanthanide ion itself, depends on both the molar extinction coefficient and also on the sensitization [13]. Since the photoluminescence spectra were obtained at different voltages on the photomultiplier, the normalized $I_{614}$ values related to $I_{614}$ of the Eu ${ }^{3+} /$ TTA complex, which is shown in Table 2.

Table 2. The $I_{614}$ values for complexes of $\mathrm{Eu}^{3+}$ with $4-\mathrm{AM}-\mathrm{VPA}, \mathrm{TTA}$, and PHEN, in aqueous solutions.

\begin{tabular}{cc}
\hline Solution & I614 (U = 400) \\
\hline $\mathrm{Eu}^{3+} / 4-\mathrm{AM}-\mathrm{VPA}$ copolymer & $\mathrm{n} / \mathrm{d}$ \\
\hline $\mathrm{Eu}^{3+} / \mathrm{TTA}$ & 1 \\
\hline $\mathrm{Eu}^{3+} / \mathrm{PHEN}$ & $<1$ \\
\hline $\mathrm{Eu}^{3+} / 4-\mathrm{AM}-\mathrm{VPA}$ copolymer/TTA & 186 \\
\hline $\mathrm{Eu}^{3+} / 4-\mathrm{AM}-\mathrm{VPA}$ copolymer/PHEN & 72 \\
\hline $\mathrm{Eu}^{3+} / 4-\mathrm{AM}-\mathrm{VPA}$ copolymer/TTA/PHEN & 2434 \\
\hline
\end{tabular}

It has already been noted that the $\mathrm{Eu}^{3+} / \mathrm{VPA}$ polymer and the $\mathrm{Eu}^{3+} / 4-\mathrm{AM}-\mathrm{VPA}$ copolymer complexes do not exhibit significant luminescence, since the direct excitation of the $\mathrm{Eu}^{3+}$ lanthanide ion is impossible. When TTA is added to a solution of $\mathrm{Eu}^{3+} / 4-\mathrm{AM}-\mathrm{VPA}$, intense luminescence appears in the solution (Figure 10b, spectrum 2). The spectrum 
contains bands characteristic of $\mathrm{Eu}^{3+}$, with $\lambda \max =580,595,614,655$, and $702 \mathrm{~nm}$, which is related to transitions from the ${ }^{5} \mathrm{D}_{0}$ state to the ${ }^{7} \mathrm{~F}_{\mathrm{j}}(1-5) \mathrm{Eu}^{3+}$ levels, respectively.

Table 2 shows that luminescence of $\mathrm{Eu}^{3+}$ ions in the copolymer solution containing TTA or PHEN is enhanced by more than an order of magnitude as compared with that of the $\mathrm{Eu}^{3+} / \mathrm{TTA}$ in an aqueous solution at the same concentrations. The weak luminescence of the $\mathrm{Eu}^{3+} / \mathrm{TTA}$ solution is due to the low value of the formation constant of the $\mathrm{Eu}^{3+} / \mathrm{TTA}$ complex in aqueous solutions (without a polymer), where $\log \mathrm{K}=-3.4$ [32]. A similar effect is observed for the complex $\mathrm{Eu}^{3+} / 4-\mathrm{AM}-\mathrm{VPA}$ copolymer/PHEN (Figure 10c, spectrum 2).

The enhanced luminescence of $\mathrm{Eu}^{3+} / \mathrm{TTA}$ or $\mathrm{Eu}^{3+} / \mathrm{PHEN}$ in a solution of a polymer complex, the so-called "polymer effect", is due to the displacement of water molecules from the coordination sphere of a low molecular complex and the substitution of a part of the water molecules by copolymer phosphonate groups.

In a number of publications [33-35], it has been demonstrated that an increase in europium luminescence intensity may be caused by the formation of mixed-ligand complexes. As it is seen in Figure 10, introducing PHEN to the solution of $\mathrm{Eu}^{3+} / 4-\mathrm{AM}-\mathrm{VPA}$ copolymer/TTA (in the ratio $[\mathrm{TTA}] /[\mathrm{PHEN}]=2: 1$ ) leads to an increase in the luminescence intensity $I_{614}$ by more than one order of magnitude (by 13 times).

The intensity of luminescence $I_{614}$ in solutions of complexes strongly depends on the comonomer's nature. Table 3 presents the corresponding data for VPA copolymers with 4-AM, MAG, and AA of close compositions (14, 12, and 14 mol.\% of copolymer units). As can be seen, the highest luminescence intensity was found for the VPA-4-AM copolymer. Apparently, this is related to the influence of the macromolecular environment of the phosphonate fragments on its ability to bind $\mathrm{Eu}^{3+}$, TTA, and PHEN, affecting, for example, the possibility of forming $\mathrm{H}$-bonds between the units of neutral fragments and the $\mathrm{P}=\mathrm{O}$ group in the copolymer, which can lead to a change in the binding constants of both $\mathrm{Eu}^{3+}$ ions and neutral ligands.

Table 3. The $I_{614}$ values for complexes of $\mathrm{Eu}^{3+}$ with VPA copolymers in aqueous solutions in the presence of sensitizers.

\begin{tabular}{ccccc}
\hline $\begin{array}{c}\mathbf{N} \\
\text { (Table } 1)\end{array}$ & $\mathbf{M}_{\mathbf{2}}$ & $\begin{array}{c}\boldsymbol{I}_{\mathbf{6 1 4}} \\
\text { Copolymer/TTA }\end{array}$ & $\begin{array}{c}\boldsymbol{I}_{\mathbf{6 1 4}} \\
\text { Copolymer/TTA/PHEN }\end{array}$ & $\boldsymbol{I}_{\text {TTA+PHEN }} / \mathbf{I}_{\text {TTA }}$ \\
\hline 5 & $4-\mathrm{AM}$ & 92 & 1272 & 14 \\
\hline 3 & MAG & 18 & 944 & 52 \\
\hline 11 & AA & 3 & 204 & 68 \\
\hline
\end{tabular}

To summarize, the synthesized copolymers form complexes with $\mathrm{Eu}^{3+}$ that demonstrate the intense red luminescence.

\section{Conclusions}

Copolymers of vinylphosphonic acid (VPA) with 2-deoxy-2-methacrylamido-D-glucose and 4-acryloylmorpholine were synthesized for the first time; copolymers of VPA with acrylamide were also prepared. The products contained from 6 to 97 mol.\% of VPA, and the molecular masses of the synthesized copolymers varied from $5 \times 10^{3}$ to $310 \times 10^{3}$. The reactivity ratios of vinylphosphonic acid and 2-deoxy-2-methacrylamido-D-glucose in copolymerization were determined, and it was found that vinylphosphonic acid was less active in these copolymerization processes than other comonomers. The resulting copolymers contained lower amounts of VPA units than the initial comonomer mixture in all cases. An increase in the VPA concentration in the initial mixture led to a decrease in the copolymer yield and molecular masses. Copolymerization in aqueous solutions yielded products with higher molecular masses than copolymerization in organic solvents (2,2-dimethylformamide or methanol).

It was demonstrated that the synthesized copolymers form complexes with $\mathrm{Eu}^{3+}$ ions in the presence of thenoyltrifluoroacetone and phenanthroline, while the intensity of the 
luminescence of these complexes in solutions in the long-wavelength region depends on the comonomer nature (2-deoxy-2-methacrylamido-D-glucose, 4-acryloylmorpholine, or acrylamide).

Author Contributions: Conceptualization, O.N. and E.P.; methodology, O.N., T.N., A.D. and E.V.; investigation, E.C., Y.Z., A.F. and M.B.; writing-original draft preparation, O.N. and T.N.; writingreview and editing, O.N., T.N., A.D., E.V. and Y.Z.; supervision, E.P.; funding acquisition, E.P. All authors have read and agreed to the published version of the manuscript.

Funding: This research was funded by the Ministry of Science and Higher Education of the Russian Federation, grant number 075-15-2020-794.

Institutional Review Board Statement: Not applicable.

Informed Consent Statement: Not applicable.

Conflicts of Interest: The authors declare no conflict of interest.

\section{References}

1. Macarie, L.; Ilia, G. Poly(Vinylphosphonic Acid) and Its Derivatives. Prog. Polym. Sci. 2010, 35, 1078-1092. [CrossRef]

2. Ingratta, M.; Elomaa, M.; Jannasch, P. Grafting Poly(Phenylene Oxide) with Poly(Vinylphosphonic Acid) for Fuel Cell Membranes. Polym. Chem. 2010, 1, 739. [CrossRef]

3. Ellis, J.; Anstice, M.; Wilson, A.D. The Glass Polyphosphonate Cement: A Novel Glass-Ionomer Cement Based on Poly(Vinyl Phosphonic Acid). Clin. Mater. 1991, 7, 341-346. [CrossRef]

4. Dey, R.E.; Zhong, X.; Youle, P.J.; Wang, Q.G.; Wimpenny, I.; Downes, S.; Hoyland, J.A.; Watts, D.C.; Gough, J.E.; Budd, P.M. Synthesis and Characterization of Poly(Vinylphosphonic Acid-Co-Acrylic Acid) Copolymers for Application in Bone Tissue Scaffolds. Macromolecules 2016, 49, 2656-2662. [CrossRef]

5. Jiang, X.; Li, Z.; Young, D.J.; Liu, M.; Wu, C.; Wu, Y.-L.; Loh, X.J. Toward the Prevention of Coronavirus Infection: What Role Can Polymers Play? Mater. Today Adv. 2021, 10, 100140. [CrossRef]

6. Schandock, F.; Riber, C.F.; Röcker, A.; Müller, J.A.; Harms, M.; Gajda, P.; Zuwala, K.; Andersen, A.H.F.; Løvschall, K.B.; Tolstrup, M.; et al. Macromolecular Antiviral Agents against Zika, Ebola, SARS, and Other Pathogenic Viruses. Adv. Healthc. Mater. 2017, 6, 1700748. [CrossRef]

7. Rivas, B.L.; Pereira, E.; Gallegos, P.; Homper, D.; Geckeler, K.E. Metal Ion Binding Capability of the Water-Soluble Poly(Vinyl Phosphonic Acid) for Mono-, Di-, and Trivalent Cations. J. Appl. Polym. Sci. 2004, 92, 2917-2922. [CrossRef]

8. Louzoun-Zada, S.; Jaber, Q.Z.; Fridman, M. Guiding Drugs to Target-Harboring Organelles: Stretching Drug-Delivery to a Higher Level of Resolution. Angew. Chem. Int. Ed. 2019, 58, 15584-15594. [CrossRef]

9. Bünzli, J.-C.G. Lanthanide Light for Biology and Medical Diagnosis. J. Lumin. 2016, 170, 866-878. [CrossRef]

10. Khandare, J.; Minko, T. Polymer-Drug Conjugates: Progress in Polymeric Prodrugs. Prog. Polym. Sci. 2006, 31, 359-397. [CrossRef]

11. Clearfield, A. Coordination Chemistry of Phosphonic Acids with Special Relevance to Rare Earths. J. Alloys Compd. 2006, 418, 128-138. [CrossRef]

12. Weissman, S.I. Intramolecular Energy Transfer the Fluorescence of Complexes of Europium. J. Chem. Phys. 1942, 10, 214-217. [CrossRef]

13. Utochnikova, V.V. The Use of Luminescent Spectroscopy to Obtain Information about the Composition and the Structure of Lanthanide Coordination Compounds. Coord. Chem. Rev. 2019, 398, 113006. [CrossRef]

14. Nekrasova, T.N.; Zhuravskaya, O.N.; Bezrukova, M.A.; Dobrodumov, A.V.; Panarin, E.F. Water-Soluble Polymer Ligands for Binding of Terbium Ions. Dokl. Chem. 2020, 492, 85-88. [CrossRef]

15. Yılmaz, M.; Akar, A.; Köken, N.; Kızılcan, N. Polymers of Vinylphosphonic Acid, Acrylonitrile, and Methyl Acrylate and Their Nanofibers. J. Appl. Polym. Sci. 2020, 137, 49023. [CrossRef]

16. Bingöl, B.; Strandberg, C.; Szabo, A.; Wegner, G. Copolymers and Hydrogels Based on Vinylphosphonic Acid. Macromolecules 2008, 41, 2785-2790. [CrossRef]

17. Kim, S.J.; Jang, J. Synergistic UV-Curable Flame-Retardant Finish of Cotton Using Comonomers of Vinylphosphonic Acid and Acrylamide. Fibers Polym. 2017, 18, 2328-2333. [CrossRef]

18. Kavlak, S.; Güner, A.; Rzayev, Z.M.O. Functional Terpolymers Containing Vinylphosphonic Acid: The Synthesis and Characterization of Poly(Vinylphosphonic Acid-Co-Styrene-Co-Maleic Anhydride). J. Appl. Polym. Sci. 2012, 125, 3617-3629. [CrossRef]

19. Erdemi, H.; Bozkurt, A. Synthesis and Characterization of Poly(Vinylpyrrolidone-Co-Vinylphosphonic Acid) Copolymers. Eur. Polym. J. 2004, 40, 1925-1929. [CrossRef]

20. Bozkurt, A.; Meyer, W.H.; Gutmann, J.; Wegner, G. Proton Conducting Copolymers on the Basis of Vinylphosphonic Acid and 4-Vinylimidazole. Solid State Ion. 2003, 164, 169-176. [CrossRef]

21. Wagner, T.; Manhart, A.; Deniz, N.; Kaltbeitzel, A.; Wagner, M.; Brunklaus, G.; Meyer, W.H. Vinylphosphonic Acid Homo- and Block Copolymers: Vinylphosphonic Acid Homo- and Block Copolymers. Macromol. Chem. Phys. 2009, 210, 1903-1914. [CrossRef] 
22. Korzhikov, V.A.; Diederichs, S.; Nazarova, O.V.; Vlakh, E.G.; Kasper, C.; Panarin, E.F.; Tennikova, T.B. Water-Soluble AldehydeBearing Polymers of 2-Deoxy-2-Methacrylamido-D-Glucose for Bone Tissue Engineering. J. Appl. Polym. Sci. 2008, 108, $2386-2397$. [CrossRef]

23. Tsvetkov, V.N. Transport Methods. In Rigid-Chain Polymers. Hydrodynamic and Optical Properties in Solution; Consultants Bureau: New York, NY, USA, 1989; pp. 87-146, ISBN 978-0-306-11020-7.

24. Macarie, L.; Pekar, M.; Simulescu, V.; Plesu, N.; Iliescu, S.; Ilia, G.; Tara-Lunga-Mihali, M. Properties in Aqueous Solution of Homoand Copolymers of Vinylphosphonic Acid Derivatives Obtained by UV-Curing. Macromol. Res. 2017, 25, 214-221. [CrossRef]

25. Hamai, R.; Shirosaki, Y.; Miyazaki, T. Biomineralization Behavior of a Vinylphosphonic Acid-Based Copolymer Added with Polymerization Accelerator in Simulated Body Fluid. J. Asian Ceram. Soc. 2015, 3, 407-411. [CrossRef]

26. Nandi, U.S.; Ghosh, P.; Palit, S.R. Water as a Chain-Transferring Agent in Vinyl Polymerization. Nature 1962, 195, 1197-1198. [CrossRef]

27. Lelyukh, A.I.; Ushakova, V.N.; Panarin, E.F. Effect of Solvent on Molecular Weight of Polyvinylpyrrolidone in Radiation-Initiated Vinylpyrrolidone Polymerization with Low Conversions. Russ. J. Appl. Chem. 1995, 68, 82-85.

28. Fineman, M.; Ross, S.D. Linear Method for Determining Monomer Reactivity Ratios in Copolymerization. J. Polym. Sci. 1950, 5, 259-262. [CrossRef]

29. Kelen, T.; TÜd[Otilde]s, F. Analysis of the Linear Methods for Determining Copolymerization Reactivity Ratios. I. A New Improved Linear Graphic Method. J. Macromol. Sci. Part A-Chem. 1975, 9, 1-27. [CrossRef]

30. Bingöl, B.; Meyer, W.H.; Wagner, M.; Wegner, G. Synthesis, Microstructure, and Acidity of Poly(Vinylphosphonic Acid). Macromol. Rapid Commun. 2006, 27, 1719-1724. [CrossRef]

31. Latva, M.; Takalo, H.; Mukkala, V.-M.; Matachescu, C.; Rodríguez-Ubis, J.C.; Kankare, J. Correlation between the Lowest Triplet State Energy Level of the Ligand and Lanthanide(III) Luminescence Quantum Yield. J. Lumin. 1997, 75, 149-169. [CrossRef]

32. Arnaud, N.; Georges, J. Comprehensive Study of the Luminescent Properties and Lifetimes of Eu ${ }^{3+}$ and Tb3+ Chelated with Various Ligands in Aqueous Solutions: Influence of the Synergic Agent, the Surfactant and the Energy Level of the Ligand Triplet. Spectrochim. Acta Part A Mol. Biomol. Spectrosc. 2003, 59, 1829-1840. [CrossRef]

33. Kalinovskaya, I.V. Spectral-Luminescence Properties of Europium(III) Compounds with Two Different $\beta$-Diketones. Opt. Spectrosc. 2018, 124, 298-301. [CrossRef]

34. Zhuravlev, K.P.; Tsaryuk, V.I.; Pekareva, I.S.; Sokolnicki, J.; Klemenkova, Z.S. Europium and Terbium Ortho-, Meta-, and ParaMethoxybenzoates: Structural Peculiarities, Luminescence, and Energy Transfer. J. Photochem. Photobiol. A Chem. 2011, 219, 139-147. [CrossRef]

35. Tsaryuk, V.I.; Zhuravlev, K.P.; Vologzhanina, A.V.; Kudryashova, V.A.; Zolin, V.F. Structural Regularities and Luminescence Properties of Dimeric Europium and Terbium Carboxylates with 1,10-Phenanthroline $(\mathrm{CN}=9)$. J. Photochem. Photobiol. A Chem. 2010, 211, 7-19. [CrossRef] 